\title{
Manfaat Wind Display di Ruang Control Tower Terkait Keselamatan Penerbangan di Bandar Udara Hang Nadim Batam
}

\author{
Dhian Supardam \\ Ariyono Setiawan \\ Kukuh Tri Prasetyo \\ Akademi Teknik dan Keselamatan Penerbangan Surabaya \\ J1 Jemur Andayani 1/73 Surabaya 60236 \\ E-mail: dhians14.dd@gmail.com
}

\begin{abstract}
An Air Traffic Controller professionalism is required in the context of efforts to provide Air Traffic Services in order to create the Five Objectives of Air Traffic Service that affect the parameters of a standard of transport services. The problems underlying the need for certainly the very facility that is in control towers in accordance with ICAO document. The purpose of this final task is to understand how the standard tower control room facilities at Hang Nadim Airport Batam in order to improve the quality of Air Traffic Services. Behind the success of the aviation world, especially in the Hang Nadim airport Batam is inseparable from the important role of aviation-related units one of which is a wizard Air Traffic Controller (ATC). ATC has a responsibility in the provision of Air Traffic Services as outlined in the Five Objectives of Air Traffic Service. Behind the success of ATC in the provision of air traffic services can not be separated from the facilities that support their work performance, especially in space where ATC Control Tower provides Air Traffic Services. Batam's Hang Nadim Airport has great potential to become an airport that could benefit Indonesia in the world of aviation. However, it is hampered by the lack of wind facilities in the display space control tower as the air traffic service requirements as listed in Annex 11 ATS chapter 7 . Air Traffic Service requirements for information point 7.1.4.3 stating that ATC should provide the information contained wind conditions at the site by looking at the wind display. On this thesis research to try to conduct research on the need for improved facilities and the unavailability of the space control tower is deemed not a standard by the applicable ICAO documents. Associated with an increase in the provision of Air Traffic Services at Hang Nadim Airport Batam.
\end{abstract}

Key Words: wind display, air traffic service, flight safety

\section{Pendahuluan}

Pelayanan operasional penerbangan merupakan suatu kegiatan yang berkaitan dengan penggunaan wilayah udara, pesawat udara, Bandar Udara, angkutan udara, keamanan dan keselamatan penerbangan serta kegiatan dan fasilitas la in yang terkait. Oleh sebab itu, peran sumber daya manusia yang profesional dalam menjalankan kegiatan penerbangan dengan didukungnya fasilitas-fasilitas yang dapat membuat kelancaran suatu kegiatan penerbangan berdasarkan legalitas yang telah ditetapkan oleh undang - undang negara Republik Indonesia dengan mengacu kepada aturan internasional yang dibuat oleh "International Civil Aviation Organisation (ICAO) “.

Pemandu Lalu Lintas Udara ( Air Traffic Controller) adalah tenaga terdidik yang bertugas untuk memberikan pelayanan lalu lintas udara disuatu wilayah udara yang berada di bawah pengawasannya. Pokok tujuan pelayanan lalu lintas udara tercantum dalam "five objectives of Air Traffic Services " adalah memberikan pelayanan lalu lintas udara yang aman, nyaman, dan efisien. Saat ini pemandu lalu lintas udara dibagi dalam tiga unit berdasarkan wilayah pemanduannya yaitu Aerodrome Control Tower (ADC), Approach Control Office (APP) dan Area Control Centre (ACC).

Berbagai kendala yang banyak terjadi di dunia penerbangan juga tidak lepas dari kurangnya fasilitasfasilitas yang ada, baik fasilitas didalam ruang kerja petugas lalu lintas udara dimana fasilitas tersebut 
digunakan oleh petugas lalu lintas udara untuk memberikan pelayanan pelayanan penerbangan, maupun fasilitas yang ada pada area landasan yang berfungsi untuk memberikan kenyamanan dan kelancaran suatu kegiatan penerbangan tersebut.

Bandar Udara Hang Nadim Batam merupakan Bandara yang dike lola dan dikembangkan oleh Badan Pengusahaan Batam serta teknis operasionalnya bekerja sama dengan Direktorat Jenderal Perhubungan Udara Kementerian Perhubungan, Bandar Hang Nadim Batam mempunyai petugas Lalu Lintas Udara sebanyak 20 orang yang bertugas di Aerodrome Control Tower (ADC) dan memiliki tanggung jawab dalam pemberian pelayanan lalu lintas udara seperti yang tertera di Annex 11 Chapter 2 point 2.2 Objective of air traffic services.

Dalam mewujudkan pelayanan pemanduan lalu lintas udara yang optimal, dibutuhkan pula fasilitasfasilitas pendukung yang dapat menunjang kelancaran operasi penerbangan. Berkaitan dengan hal tersebut untuk memberikan pelayanan bagi para pengguna jasa transportasi udara harus mengutamakan keamanan dan keselamatan penerbangan. Namun dalam kenyataannya di Bandar Udara Hang Nadim Batam ditemui adanya berbagai macam kendala yang menyebabkan pemberian pelayanan lalu lintas udara yang kurang optimal khususnya fasilitas di ruang Control Tower dalam pemberian pelayanan informasi kondisi angin. Dalam hal ini pesawat-pesawat yang akan melakukan lepas landas dan mendarat membutuhkan informasi angin yang akurat. Di dalam kenyataannya Bandar Udara Hang Nadim Batam hanya mengandalkan fasilitas windsock sebagai sarana pemberian informasi angin. Hal ini sangat berpengaruh terhadap keselamatan kegiatan penerbangan.

Rumusan masalah dalam penelitian ini adalah manfaat wind display di ruang control tower sebagai upaya peningkatan Pelayanan Lalu Lintas Udara di Bandar Udara Hang Nadim Batam?

\section{Tinjauan Teori}

\section{Teori yang Mendukung}

Bandar Udara Hang Nadim Batam saat ini melayani penerbangan sipil baik berjadwal maupun tidak berjadwal, militer dan penerbangan untuk latihan (training flight).

Bandar Udara Hang Nadim Batam adalah bandar udara yang memiliki volume traffic yang cukup padat, namun dalam pemberian pelayanan lalu lintas udara masih kurang optimal khususnya pada unit Control Tower dimana masih terkendala dengan tidak adanya fasilitas wind display.

Selama ini Air Traffic Controller (ATC) memberikan pelayanan lalu lintas udara khususnya dalam pemberian informasi wind untuk pesawat yang take off atau landing hanya pengamatan dari windsock yang berupa informasi arah angin sejak tidak adanya fasilitas wind display di tower Hang Nadim sekitar 10 tahun terakhir yang rusak akibat terkena petir saat hujan lebat. Windsock hanya berupa kain yang berbentuk menyerupai tabung atau corong. Kondisi windsock basah saat terkena hujan berbeda dengan kondisi windsock yang kering. Berikut merupakan gambar windsock:

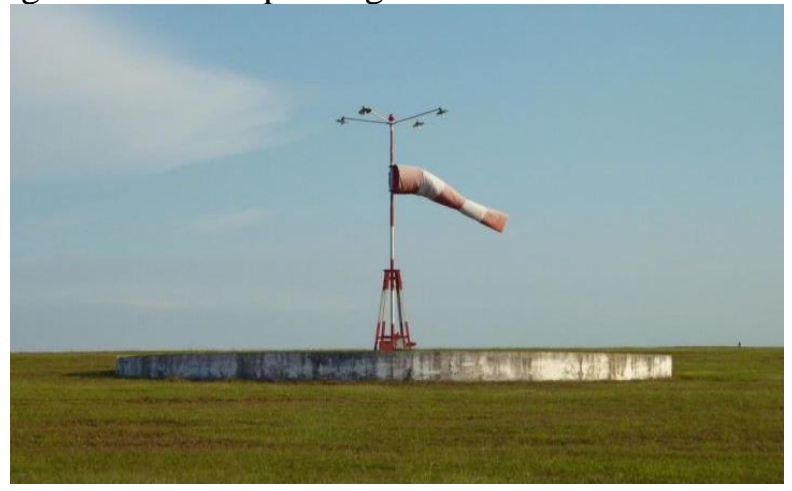

Gambar 1 : Windsock

Sumber : Bandar Udara Hang Nadim Batam

Hal demikian akan sangat mempengaruhi pemberian pelayanan informasi arah angin untuk pesawat yang akan take off dan landing. Dijelaskan di Annex 3 Meteorological Service for International Air Navigation Chapter 4 poin 4. 5. 1 Observing and reporting of surface wind bahwa "The mean direction 
and the mean speed of the surface wind should be measured, as well as sign ificant variations of the wind direction and speed. Since, in practice, the surface wind cannot be measured directly on the runway, surface wind observations for take-off and landing should be the best practicable indication of the winds which an aircraft will encounter during take-off and landing." Menjelaskan bahwa penentuan landasan pacu yang akan digunakan untuk penerbangan dan pesawat yang akan mendarat ataupun lepas landas sangat membutuhkan informasi angin yang akurat. Selain itu petugas Air Traffic Controller (ATC) hanya mengandalkan informasi dari unit Meteorologi khususnya unit observer melewati Automatic Terminal Information Service (ATIS) yang datanya diperbarui setiap 30 menit untuk mengetahui kecepatan angin. Meskipun kenyataannya kecepatan dan arah angin selalu berubah-ubah setiap waktu. Adapun tugas unit observer stasiun Meteorologi sesuai hasil pengamatan adalah: menit.

a) Membuat informasi weather untuk kepentingan take off dan landing pesawat (QAM) setiap 30

b) Membuat Meteorology Aviation Routine (METAR) setiap satu jam yang dikirim melalui AFTN.

c) Membuat Synoptic setiap satu jam dan tiga jam sekali dikirim ke Collecting Centre BMG untuk keperluan data forecast.

Berdasarkan Annex 3 Meteorological Service for International Air Navigation Appendix 3. Criteria For Reporting Meteorological and

Related Parameters in Automated Air - Reports, berikut adalah kriteria untuk pelaporan data atau informasi cuaca oleh unit Meteorologi meliputi:

1. Wind direction

The wind direction shall be reported in terms of degrees true, rounded to the nearest whole degree.

2. Wind speed

The wind speed shall be reported in kilometres per hour or knots, rounded to the nearest $2 \mathrm{~km} / \mathrm{h}(1$

knot). The units used shall be indicated.

3. Wind quality flag

4. Temperature

The wind quality flag shall be reported as 0 when the roll angle is less than 5 degrees and as 1 when the roll angle is 5 degrees or more. The temperature shall be reported to the nearest tenth of a degree Celsius.

Dari permasalahan yang telah dibahas penulis, dapat disimpulkan bahwa masih perlunya peningkatan fasilitas pelayanan lalu lintas udara terkait dengan tidak adanya fasilitas wind display di ruang control tower Bandar Udara Hang Nadim Batam.

Seperti yang dijelaskan pada dokumen 9426 ATS Planning Manual Part III Chapter 2 poin 2.3.8 bahwa "The aerodrome lighting control panel should be incorporated in a cab console or in a separate desk. The ILS monitor panel/alarm should also be mounted in the cab console but can be in a less utilized area. Radio and telephone selector panels should be installed at the control positions and should include emergency and other special use telephone equipment. Depending on their number and personal preference, radio speakers may be mounted in the consoles or a special overhead rack suspended from the ceiling. Other cab equipment includes wind direction and speed indicators, altimeter readout indicator, light-gun(s) and clock(s) and, where required, remote runway tempera- ture readout. Where the tower personnel have been assigned the additional responsibility for making partial weather observations, cloud height and temperature indicators should be included". Jadi, letak atau posisi wind dispay terlihat di desk control pada ruang control tower bandar udara Hang Nadim Batam. Arus lalu lintas udara di Bandar Udara Hang Nadim Batam semakin padat, seiring bertambahnya arus lalu lintas udara maka semakin banyak potensi permasalahan yang dapat terjadi, sehingga pemberian pelayanan harus ditingkatkan.

Adapun teori yang mendukung berkaitan dengan fasilitas yang berada di ruang control tower sebagai syarat pemberian pelayanan lalu lintas udara, yaitu belum adanya wind display di Hang Nadim Batam, seperti yang tercantum pada Annex 11 ATS chapter 7. Air Traffic Services Requirements For Information point 7.1.4.3 Aerodrome control tower shall be equipped with surface wind doslpay(s). The display(s) shall be related to the same location(s) of observation and be fed from the same sensor(s) as the 
corresponding display(s) in the meteorological station,where such a station exists.where multiple sensor(s) are used, the displays to which they are related shall be clearly marked to identify the runway and section of the runway monitored by each sensor.

Di jelaskan juga di CASR 170 Sub Part 170.F Informasi Yang Di butuhkan ATS (Air Traffic Service) point 53 No $4 a, b, c, d, e, f, g$ yang inti dari isi tersebut menyatakan bahwa Aerodrome Control Tower $(A D C)$ di lengkapi oleh fasilitas yang berhubungan dengan kondisi cuaca.

Dari teori pendukung tentang fasilitas di ruang control tower sebagai syarat pemberian pelayanan lalu lintas udara diatas berkaitan dengan Five Objectives of air Traffic Service dimana fasilitas tersebut sangat dibutuhkan untuk meningkatkan Pelayanan Lalu Lintas Udara di Bandar Udara Hang Nadim Batam, dan apabila fasilitas tersebut tidak ada di ruang control tower, ada kemungkinan terjadinya Human Error seperti yang tercantum pada Human error in air Traffic Control DIGEST No.8 ICAO Circular yang menyebutkan bahwa Controller dalam melakukan tugas-tugasnya harus dibantu dengan peralatan, dan harus berdasarkan dokumen, peraturan-peraturan, serta melihat, mendengar dan menyampaikan instruksi / clearance kepada penerbang (Pilot).

\section{Pembahas an Masalah}

Bandar Udara Hang Nadim Batam memiliki potensi besar untuk menjadi bandar udara yang dapat memberikan peluang yang besar baik dari sisi ekonomi dan penerbangan. Namun demikian keberadaan potensi yang ada harus diimbangi dengan pemberian pelayanan lalu lintas udara oleh personel Air Traffic Controller, berdasarkan dokumen ICAO annex 11, personel Air Traffic Control wajib diberikan pelayanan lalu lintas udara yang diantaranya adalah sebagaiberikut:

1. Pelayanan lalu lintas udara (Air Traffic Control Service) :

Terdiri dari aerodrome control tower, approach control service, dan area control service. Sedangkan yang dimaksud dengan pelayanan aerodrome control tower adalah pelayanan yang memberikan pelayanan air traffic control service, flight information service, dan alerting service yang diperuntukkan bagi pesawat terbang yang beroperasi di bandar udara sekitar seperti take off, landing, taxiing, yang berada di kawasan maneuvering area yang dilakukan di menara pengawas lalu lintas udara.

2. Pelayanan informasi penerbangan (Flight information service):

Flight Information Service adalah pelayanan yang dilakukan dengan memberikan berita dan informasi yang berguna dan bermanfaat seperti weather information, traffic information, navigation information untuk keselamatan, keamanan, dan efisiensi bagi penerbangan.

3. Pelayanan keadaan darurat (Alerting service) :

Alerting Service adalah pelayanan yang dilakukan dengan memberitahukan kepada unit operasional terkait secara internal khusunya yang bertanggung jawab terhadap pelayanan keadaan darurat serta instansi terkait mengenai pesawat udara yang membutuhkan pertolongan unit search and rescue dan membantu instansi tersebut apabila diperlukan.

Ketiga pelayanan tersebut dilakukan oleh unit Pemandu Lalu Lintas Udara yang diisi oleh para Air Traffic Controller agar dapat mewujudkan tujuan kelancaran dan keselamatan penerbangan.

Menurut petugas Pimpoksi unit PLLU di Bandar Udara Hang Nadim Batam, menyatakan bahwa dengan keadaan cuaca di Batam, maka selama ini ATC Bandar Udara Hang Nadim Batam dalam pemberikan pelayanan lalu lintas udara khususnya pemberian informasi cuaca ( Current Weather Report / $Q A M$ ) dan untuk current surface wind hanya bisa diamati dari fasilitas windsock, sedangkan informasi angin yang diberikan windsock kurang akurat. Sangat diperlukan fasilitas wind display guna memperoleh data arah dan kecepatan angin secara akurat. Ketidakakuratan data berdasarkan hasil pengamatan dari windsock dan Automatic Terminal Information Service (ATIS) dapat dibuktikan dengan beberapa laporan kejadian terkait perbedaan infomasi QAM yang diberikan oleh Air Traffic Controller (ATC) on duty dengan kenyataan yang dialami oleh penerbang sebagai berikut : 
Tabel 1

Contoh Kasus tahun 2010

\begin{tabular}{|c|c|c|c|}
\hline No & Tanggal Kejadian & Operator/Airline & Kejadian \\
\hline 1 & 12 Eebruari 2010 & BATAVIA AIR & Terkena Tail Wind \\
\hline 2 & 21 April 2010 & SUSI AIR & $\begin{array}{l}\text { Go around akibat angin } \\
\text { kencang di runway } 04\end{array}$ \\
\hline 3 & 4 Agustus 2010 & WINGS AIR & Terkena Tail Wind \\
\hline 4 & 11 Oltober 2010 & LIONAIR & $\begin{array}{l}\text { Terkena angin kencang di } \\
\text { long final runvay } 22\end{array}$ \\
\hline 5 & 25 Oltober 2010 & LIONAIR & $\begin{array}{c}\text { Terkena Tail Wind di final } \\
\text { runway } 04\end{array}$ \\
\hline 6 & 3 November 2010 & BATAVIA AIR & $\begin{array}{l}\text { Terdapat angin kencang di } \\
\text { long final } 22\end{array}$ \\
\hline 7 & 5 Desember 2010 & WINGSAIR & Terkena Tail Wind \\
\hline 8 & 17 Desember 2010 & LIONAIR & Terkena Tail Wind \\
\hline 9 & 26 Desember 2010 & LIONAIR & Terkena Tail Wind \\
\hline
\end{tabular}

Sumber : Log Book Hang Nadim Batam
Tabel 2

Contoh Kasus tahun 2011

\begin{tabular}{|c|c|c|c|}
\hline No & Tanggal Kejadian & Operator/Airline & Kejadian \\
\hline 1. & 16 Januan 2011 & $\begin{array}{l}\text { SRIWIJAYA } \\
\text { AIR }\end{array}$ & $\begin{array}{l}\text { Terdapat anginkencang di } \\
\text { Base Leg runway } 22\end{array}$ \\
\hline 2. & 4 Maret 2011 & MERPATI & $\begin{array}{l}\text { Go around terkena angin } \\
\text { di final nunway } 04\end{array}$ \\
\hline 3. & 11 Maret 2011 & BATAVIA AIR & Terkena Tail Wind \\
\hline 4. & 20 Maret 2011 & $\begin{array}{l}\text { SRIWIJAYA } \\
\text { AIR }\end{array}$ & Terkena Tail Wind \\
\hline 5. & 12 Mei 2011 & $\begin{array}{l}\text { GARUDA } \\
\text { INDONESIA }\end{array}$ & $\begin{array}{c}\text { Terkena Tail Wind di final } \\
\text { nunway } 04\end{array}$ \\
\hline 6. & 24 Mei 2011 & LIONAIR & $\begin{array}{c}\text { Terkena Tail Wind di final } \\
\text { nunway } 22\end{array}$ \\
\hline 7. & 17 Juni 2011 & $\begin{array}{l}\text { GARUDA } \\
\text { INDONESIA }\end{array}$ & $\begin{array}{l}\text { Terkena Cross Wind di } \\
\text { final nunway } 04\end{array}$ \\
\hline
\end{tabular}

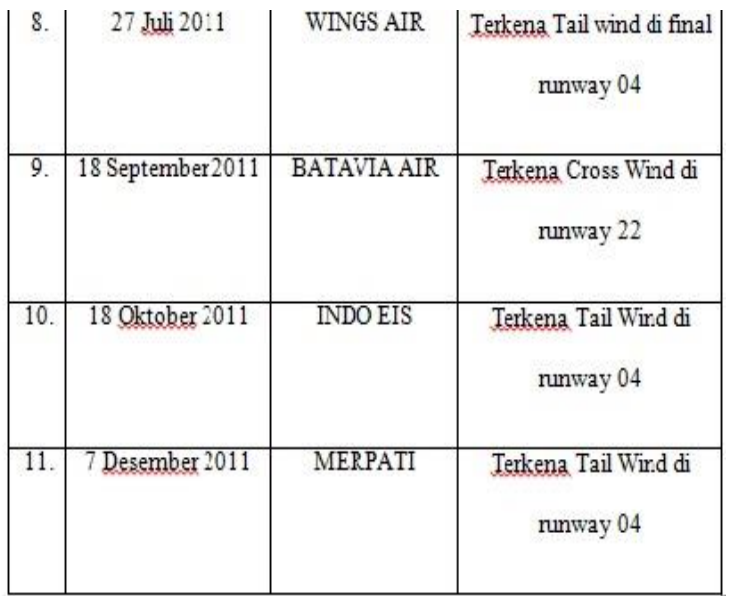

Sumber : Log Book Hang Nadim Batam 
Tabel 3

Contoh Kasus tahun 2012

\begin{tabular}{|c|c|c|c|}
\hline No & Tanggal Kejadian & Operator/Airline & Kejadian \\
\hline 1. & 19 Maret 2012 & $\begin{array}{l}\text { GARUDA } \\
\text { INDONESIA }\end{array}$ & $\begin{array}{l}\text { Terkena. Wind Shear di } \\
\text { nunway } 04\end{array}$ \\
\hline 2. & 2 Mei 2012 & LION AIR & $\begin{array}{l}\text { Terkena Tail wind di } \\
\text { nunway } 04\end{array}$ \\
\hline 3. & $18 \mathrm{Mei} 20132$ & LION AIR & $\begin{array}{l}\text { Terdapat angin kencang di } \\
\text { final nunway } 22\end{array}$ \\
\hline
\end{tabular}

Berikut merupakan perhitungan prosentase berdasarkan contoh kasus setiap tahunnya:

$$
\text { RUMUS }=\frac{\text { Rata-rata jumlah kasus }}{\text { Jumlah traffic dalam setahun }} \quad X 100 \%
$$

\section{Diketahui:}

Jumlah kasus tahun $2010=9$ kasus

Jumlah kasus tahun $2011=11$ kasus

Jumlah kasus tahun $2012=3$ kasus

23 kasus 


$$
\begin{aligned}
& \text { Rata-rata jumlah kasus dalam } 3 \text { tahun }=\underline{23} \\
& 3 \\
& =7.7 \text { kasus } \\
& \text { Jumlah traffic per bulan }=3050 \times 12 \text { bulan } \\
& =36.600 \text { traffic } \\
& \text { Prosentase kasus per tahun }=\text { Rata-rata jumlah kasus } \\
& \text { Jumlah traffic dalam setahun } \\
& \text { X } 100 \% \\
& =\frac{7.7}{36.600} \times 100 \% \\
& =\quad 0.02 \%
\end{aligned}
$$

Dari data laporan penerbang diatas diperoleh hasil bahwa dalam setiap tahun sering terdapat laporan dari penerbang yang berhubungan dengan kondisi angin yang dapat mengakibatkan $0,02 \%$ kecelakaan pesawat setiap tahunnya dan berdasarkan hasil dari kuesioner yang penulis ajukan kepada petugas Air Traffic controller (ATC) di Bandar Udara Hang Nadim Batam dan bukti laporan penerbang menyatakan bahwa fasilitas wind display di Bandar Udara Hang Nadam Batam sangat diperlukan yang dapat membantu dalam pemberian pelayanan lalu lintas udara secara akurat dibandingkan dengan fasilitas windsock dan Automatic Terminal Information Service (ATIS) yang tersedia saat ini.

Dengan adanya fasilitas wind display di ruang control tower, maka pemberian pelayanan la lu lintas udara khususnya pemberian informasi QAM dapat diberikan secara akurat untuk pesawat yang akan landing dan take off serta dapat menghindari terjadinya accident maupun incident.

\section{Pemecahan Masalah}

1. Pengadaan dan peremajaan fasilitas yang ada di ruang control tower.

Dalam alternatif ini peremajaan fasilitas yang ada di ruang control tower akan berperan penting untuk keselamatan penerbangan. Hal ini terkait dengan tidak adanya fasilitas wind display yang berguna dalam pemberian informasi QAM oleh ATC untuk pesawat take off dan landing. Fasilitas yang diperlukan dan membutuhkan peremajaan diantaranya

a. Wind speed and direction speed

Fasilitas ini berfungsi untuk mengetahui arah angin dan kecepatan angin pada saat itu atau secara real time serta mempermudah ATC untuk menentukan landasan yang digunakan. Selain itu fasilitas ini akan digunakan ATC sebagai pemberian informasi angin yang akan diberikan oleh ATC sebelum memberikan landing dan take off clearance kepada penerbang.

b. Altimeter setting indicator 
Fasilitas ini digunakan untuk mengetahui QNH altimeter setting di suatu bandar udara dan QNH altimeter setting tersebut akan diberikan kepada penerbang untuk menentukan ketinggian berdasarkan ketinggian

c. Automatic Terminal Information Service (ATIS)

Fasilitas ini digunakan untuk memberikan keadaan cuaca secara terus menerus dan akan selalu di up to date setiap setengah jam sekali. Fasilitas ini memudahkan bagi ATC dalam penyampaian cuaca untuk mengurangi beban komunikasi antara ATC dan penerbang.

Maksud dari peremajaan adalah berdasarkan data tabel 7, Jumlah pergerakan traffic tahun 2011 yang menyatakan 8 traffic per jamnya dibanding dengan pembaharuan Automatic Terminal Information Service (ATIS) yang hanya 30 menit sekali diperkirakan terdapat 4 traffic selama waktu 30 menit sehing ga diperlukan perubahan sistem operasi Automatic Terminal Information Service (ATIS) yang sebelumnya diperbarui selama 30 menit sekali menjadi 7-8 menit sekali mengingat jumlah traffic di Bandar Udara Hang Nadim Batam yang semakin padat.

2. Peremajaan fasilitas windsock dengan alat yang lebih modern

Peremajaan windsock dapat dilakukan dengan cara pemasangan alat yang lebih modern seperti sensor yang dapat disambungkan dengan sebuah monitor yang berada di ruang control tower yang dapat memberkan informasi QAM secara akurat. Sehingga pergerakan windsock akan selalu muncul dalam monitor tersebut.

3. Adanya koordinasi yang baik antara Tower Hang Nadim dengan unit Meteorologi.

Dalam alternatif ini koordinasi antar pihak ATS terkait (pihak ADC dengan Meteorologi). Koordinasi yang baik sangat dibutuhkan untuk membantu kelancaran pemberian informasi QAM secara akurat. Diharapkan unit meteorologi dapat memberikan informasi yang actual apabila terdapat perubahan angin secara mendadak dan signifikan agar petugas ATC dapat memberikan informasi perubahan angin dengan cepat yang akan diberikan ke pesawat yang akan take off dan landing.

\section{Kesimpulan dan Keterbatasan \\ Kesimpulan}

Berdasarkan hasil analisis data yang telah dilakukan maka kesimpulan dari penelitian ini adalah bahwa tidak adanya fasilitas wind display di ruang control tower yang $0.02 \%$ dapat mengakibatkan kecelakaan bagi pesawat yang take off dan landing di Bandar Udara Hang Nadim Batam. Hasil prosentase tersebut cukup besar bagi dunia penerbangan karena sebuah kecelakaan hanya dapat terjadi sekali dalam 5 juta penerbangan.

\section{Keterbatasan}

Berdasarkan hasil penelitian, penelitian ini memiliki keterbatasan diantaranya yaitu pada saat membagikan kuesioner kepada responden, peneliti mengalami kesulitan karena tidak semua responden kooperatif untuk melakukan pengisian kuesioner, sehingga peneliti harus menunggu beberapa lama untuk mengisi kuesioner, Jadi saran peneliti di harapkan untuk penelitian selanjutnya un tuk lebih cekatan dalam membagi dan lebih berbaur dengan responden.

\section{Daftar Pustaka}

ICAO. 2001. Annex 11 Air Traffic Services.

ICAO. 2001. Annex 3 Meteorological Service for International Air Navigation

ICAO. 9426. ATS Planning Manual

ICAO Circular Human Factors Digest No. 8 : Human Factors in Air Traffic Control.

Mardalis. 1999. Metode Penelitian : Suatu Pendekatan Proposal .Ed. 1 Cet. 4. BumiAksara. Jakarta.

Riduwan. 2010. Metode dan Teknik Menyusun Tesis. Bandung: Alfabeta.

Sugiono. 2009. Metode Penelitian Adminis trasi, Alfabeta, Bandung. 